\title{
Case Conferences on Integrative Medicine - a New Tool to Improve Patient-Centred Care in Medicine
}

\author{
Benno Brinkhaus \\ Institute of Social Medicine, Epidemiology, and Health Economics, Charité University Medical Center, Berlin, Germany
}

Complementary and alternative medicine (CAM) is frequently used with patients in industrialised countries. Although the high demand for CAM and the number of CAM practitioners clearly show that CAM is very popular, there is a considerable lack of discourse and cooperation between those physicians who practise complementary medicine, those physicians who practise conventional medicine, and physicians who practise different forms of complementary medicine [1]. Moreover, there is often little or no communication between patients and their conventional physicians regarding CAM use [2]. Therefore, it is important to increase transparency and enhance communication in order to facilitate the best possible patient-oriented health care. In view of this aim the 'Dialogue Forum on Pluralism in Medicine' has introduced in 2006 a new tool for the communication between practitioners of complementary medicine and practitioners of conventional medicine, the case conference on integrative medicine (IM) [3]. The 'Dialogue Forum on Pluralism in Medicine' was founded in Germany in 2000, with the objective of initiating a structured dialogue between representatives of different therapeutic approaches, and of contributing to a patient-suitable and effective IM [4]. Since 2006, 8 case conferences have been held.

The aims of the case conferences are to facilitate the dialogue between conventional and CAM physicians and to discuss the potential of IM approaches with regard to specific patient cases. The term 'case conference' was chosen in analogy to clinical conferences in hospitals in which medical cases are presented and discussed in detail.

The case conference consists of a panel of physicians who are well-trained experts in either conventional medicine, CAM, or both, and chaired by one or two experts. Further participants admitted to the conference are physicians or individuals interested in the case and in discussing the findings with the experts. The length of each conference depends on the number of experts of conventional medicine and CAM (at least 1 expert of conventional medicine and $2 \mathrm{CAM}$ experts are required) and ranges from 90 to $180 \mathrm{~min}$ (fig. 1). After a short introducing lecture on the background, concept, and aim of the case conference, the expert panel is asked to develop integrative medical diagnoses and therapeutic strategies taking as a starting point the particular pa- tient case. The first case conferences held were about chronic disorders. In 3 cases a real patient was presented at the conference, which apparently stimulated the discussion of the case. In order to facilitate their participation in the conference, the members of the expert panel had received details on the case 2-4 weeks in advance in order to prepare their statements. After these statements, experts and audience can take the opportunity to ask the patient or the presenter for details regarding the patient's presenting history and symptoms. After presentation of the patient's case, possible diagnostic procedures and treatment options from conventional medicine and from different fields of CAM (e.g. naturopathy, homeopathy, anthroposophic medicine, acupuncture) are presented, each for $10 \mathrm{~min}$. After a short break, the experts draft dialogue possibilities between their respective field of complementary or conventional medicine in another 10 -min statement. Afterwards, experts and audience are invited to discuss common grounds and limitations of the presented treatment options as well as future treatment strategies.

The first case conference was held in December 2006 [3]. The cases of 2 patients with chronic pain diseases, one with fibromyalgia and the other with irritable bowel syndrome, were presented resulting in an interesting and constructive interchange of treatment options and discussions on how to treat these patients with IM. Initially, the discussion on definitions and boundaries between conventional and complementary treatment strategies had been fruitless and without results. However, when the focus turned to the patient and their complexity as an individual, the different points of view were brought closer together and the diversity of perspectives was perceived as a valuable resource for promoting individualisation in medical treatment. To continue this discourse further case conferences in IM were recommended. So far, a series of 6 case conferences have followed this groundbreaking conference all focusing on patients suffering from chronic diseases.

The first international case conference took place in November 2009 at the '2nd European Congress of Integrative Medicine' in Berlin, Germany. An experienced panel of experts of both conventional medicine and CAM developed integrative medical diagnoses and therapeutic strategies for a patient case with chronic

\section{KARGER}

Fax +497614520714

Information@Karger.de

www.karger.com (c) 2010 S. Karger GmbH, Freiburg

Accessible online at:

www.karger.com/fok
Prof. Dr. Benno Brinkhaus

Institute for Social Medicine, Epidemiology and Health Economics

Charité University Medical Center

10098 Berlin, Germany

Tel. +49 30450 529-002, Fax -90

benno.brinkhaus@charite.de 


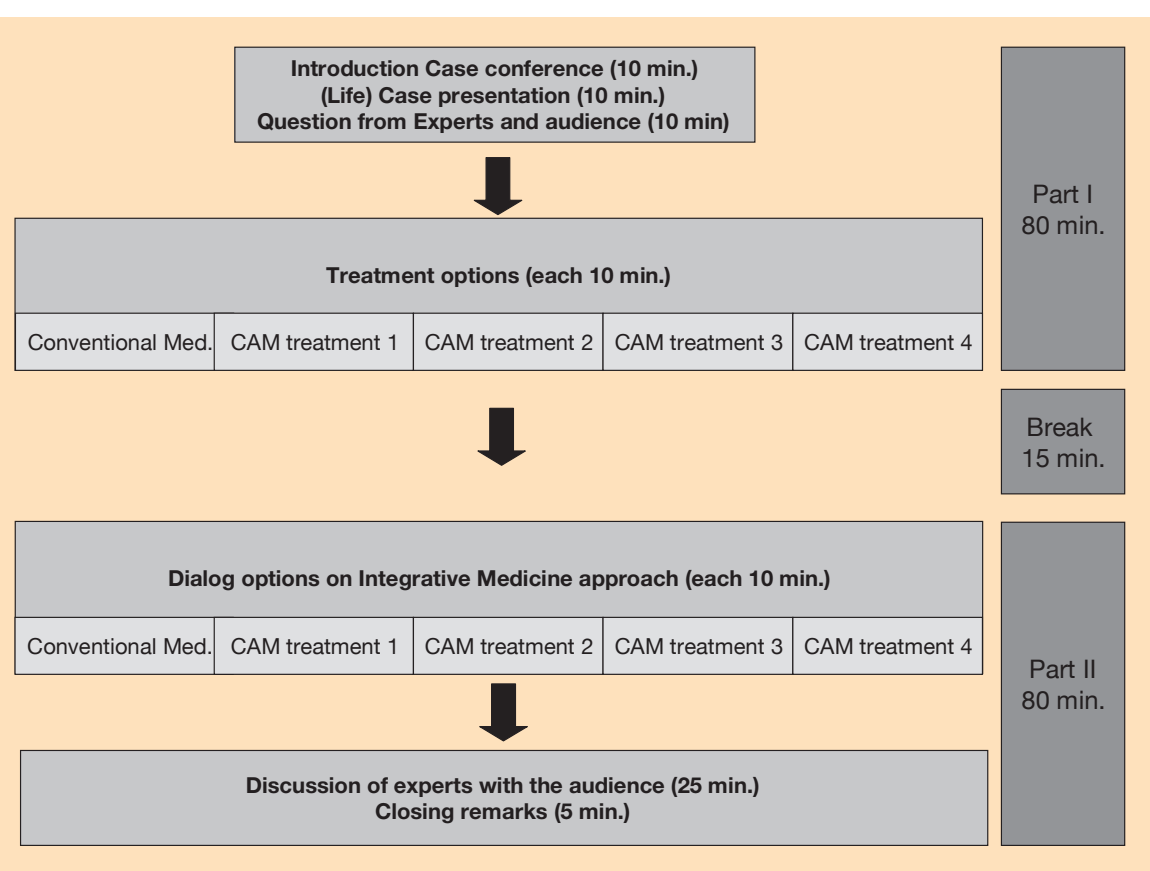

Fig. 1. Plan of a case conference.

low back pain (LBP). In this case conference, the expert panel unanimously agreed on the diagnosis of 'chronic non-specific LBP disorder with somatic and psychological factors' and suggested multi-modal short- and long-term treatment concepts that allowed an inclusion of CAM therapies. The importance of the patient-physician relationship and of a consultation process with sufficient consultation time for a successful treatment success was highlighted. There was consensus that the diagnostic process and the resulting treatment plan should focus on the patient as a whole person and take into account the meaning of the disease for the particular patient. Considerable differences among the experts were found regarding the first steps of treatment; each expert considered his individual treatment method the 'adequate treatment'.

Critics of case conferences may question whether case conferences are an adequate tool, at all. In the world of evidence-based medicine (EBM) systematic reviews and meta-analyses of randomised controlled trials (level 1) are the most important tools for medical decision making [5]. At the other end of the EBM scale, expert opinions fall to the lowest category in the conventional evidence hierarchy. Accordingly, the question seems to be obvious whether there is space for a detailed discussion of a single case of one indication in a case conference on IM for medical decision making. I think that case conferences are indeed an important tool to seek integrative treatment strategies for individual patient cases, because they offer an interactive platform for com- munication between physicians of different treatment approaches and the auditorium. In addition, they offer an opportunity for practitioners to understand a patient's situation and needs from different perspectives, underlining the importance of the patient as a whole. Treatment guidelines for specific diseases are, of course, the basis and background of such case conferences. However, treatment guidelines provide standardised treatment strategies, whereas case conferences on IM can improve in a much more individualised and patient-centred manner the approach to treating patients.

The first case conferences on IM have stimulated an intensive exchange between representatives of conventional and CAM medicine and helped clarify different treatment possibilities. This could serve as a model to evaluate similar activities in academic hospitals and establish such an approach in routine medical care. For me, case conferences on IM have the potential to improve patient-centred care in medicine.

\section{Acknowledgement}

I wish to thank all members of the Forum on Pluralism in Medicine especially those colleagues who participated intensively in the process of developing the tool 'Case Conference of Integrative Medicine': Dr. M. Girke, Prof. H. Heimpel, Prof. P.F. Matthiessen, Prof. A. Michalsen, Dr. Michael Teut, Prof. Stefan N. Willich.

\section{References}

1 Smithson J, Paterson C, Britten N, Evans M, Lewith G: Cancer patients' experiences of using complementary therapies: polarization and integration. J Health Serv Res Policy 2010;15(suppl 2):54-61.

2 Eisenberg DM, Kessler RC, Van Rompay MI, Kaptchuk TJ, Wilkey SA, Appel S et al: Perceptions about complementary therapies relative to conventional therapies among adults who use both: results from a national survey. Ann Intern Med 2001;135:344-351.

3 Brinkhaus B, Teut M, Girke M, Matthiessen PF, Michalsen A, Heimpel $\mathrm{H}$ et al: [Fall Congress for Integrative Medicine - model for the future]. Dtsch Med Wochenschr 2009;134:207-208.
4 Willich SN, Girke M, Hoppe JD, Kiene H, Klitzsch W, Matthiessen PF et al: Schulmedizin und Komplementärmedizin: Verständnis und Zusammenarbeit müssen vertieft werden. Dtsch Ärztebl 2004; 101:A1314-A1319.

5 Straus SE: Bridging the gaps in evidence based diagnosis. BMJ 2006;333:405-406. 